\title{
Implications of Metacognitive Knowledge in Indonesian Learning Teaching Materials for Foreign Speakers
}

\author{
Akbar Bagus Wicaksono ${ }^{1, *}$, Sarwiji Suwandi ${ }^{2}$, Andayani ${ }^{3}$, Mipa Tiyasmala ${ }^{4}$ \\ 1,2,3,4 Universitas Sebelas Maret, Surakarta, Indonesia \\ *Corresponding author.Email: wicaksono.akbarbagus@student.uns.ac.id
}

\begin{abstract}
This research is expected to be able to reveal the contribution of the metacognitive aspects contained in a teaching material so that it can raise the metacognitive abilities of foreign students in achieving success in learning Indonesian. Metacognition which is commonly known as life, mental activity or process and emotional construction occurring in the brain is one of the aspects driving individual behavior so that the development of good metacognitive aspects will support the process of forming 4 (four) skills needed in the 21st century; problem solving skills, decision making, critical thinking, and creative thinking. This research examines 6 BIPA Textbooks. The research uses document analysis method with a theory triangulation validation. The research resulted in findings on declaration, procedural, and conditional knowledge which are the structures of metacognitive knowledge in the realm of language, culture, and general knowledge.
\end{abstract}

Keywords: Metacognitive, Indonesian Language

\section{INTRODUCTION}

The development of good metacognitive aspects will support the process of forming 4 (four) skills needed in the 21st century such as problem solving, decision making, critical thinking, and creative thinking [1]. Livingston (1997) states that metacognition is based on high-level thinking and involves active control of the cognitive processes supporting the learning process [2].

Wellman (1985) stated that metacognition is a form of cognitive activity at a higher level involving active control of the cognitive system so that the development of good metacognitive aspects will support the process of forming 4 (four) skills needed in the 21 st century such as problem solving skills, decision making, critical thinking, and creative thinking [1] [3].

The study by OZ (2016) found that there is high metacognitive awareness in 7 out of 10 participants for metacognitive knowledge $(65 \%)$ and metacognitive regulation $(63 \%)$. Implicitly, the result reveals a significant relationship between metacognitive awareness and academic motivation [4]. Tamalene (2010) suggests that metacognitive activity occurs when students consciously adjust and manage their thinking strategies while solving problems and thinking about something [5].

In line with research developed by Koning, Rop, and Paas (2020), the result shows teaching materials constructed using mental learning strategies are more effectively used to assist learners in integrating knowledge, rather than using strategies involving physical action [6]. O'Neil \& Brown (1997) states that metacognition is a process in which a person thinks about thinking in order to develop strategies for solving problems [7].

Anderson and Kathwohl (2001) stated that metacognitive knowledge is knowledge about cognition, generally the same as awareness and knowledge of one's self-cognition [8]. Metacognition involves thinking about a person's thinking or cognition, which aims to enhance learning [9]. Proust (2013) stated tha the sensitivity of the metacognitive context allows a person to have better adaptive control [9].

Jones (2003) suggested how individuals are able to manage metacognition so that it can affect their communication [10]. These abilities include: (a) individuals can understand that they have a mind with the capacity to think extraordinary consciously which they can develop; (b) individuals can be more efficient in thinking about their thoughts if they view their mental processes as skills they can practice; and (c) in everyday life, individuals can practice diligently using mental skills to influence their communication.

According to Gourgey (in Kilinc, 2013) metacognition is awareness of how a person learns, awareness when someone understands and is not 
understood, knowledge of how to use available information to achieve goals, the ability to assess cognitive needs in various exercises, knowledge of the strategies used to achieve goals, measure one's progress either during or after it is done [11]. Metacognition involves thinking about a person's thinking or cognition which aims to enhance learning [9]. Abdellah (2015) found a positive relationship between cognitive awareness and academic achievement as measured by the achievement index [12].

\section{METHODS}

This research is descriptive qualitative with natural setting which basically describes qualitatively in the form of words and not mathematical or statistical numbers (Lindlof, 1994) [13]. The strategy used in this research is content analysis. The basic approach of qualitative content analysis is to maintain the strength of quantitative content analysis and this background develops systematic and qualitative oriented text analysis techniques (Mayring, 2014) [14]. Qualitative researchers collect various forms of data, such as interviews, observations, and documents, rather than relying on a single source of data [15] [20].

The qualitative method in this research uses document analysis (paper or electronic) [16]. So, it is done to expand the scope of the use of many different theoretical approaches [17]. The data analysis used in this research is an interactive model which is developed by researchers in a personal process based on metacognitive themes, including thematic analysis [18]. Thematic analysis differs from other forms of content analysis [19].

\section{RESULTS}

Metacognitive knowledge refers to general knowledge about how humans learn and process information, as well as individual knowledge about the process of solving language problems themselves.

a) Declarative Knowledge

Declarative knowledge refers to knowledge of facts and concepts of vocabulary mastery (for example) that a person has or the factors affecting their thinking and attention in solving language skills problems in life.

Table 1. Percentage of Declarative Knowledge Composition in Indonesian Language for Foreigners (BIPA) books

\begin{tabular}{|l|l|l|l|l|l|l|l|}
\hline & A1 & A2 & B1 & B2 & C1 & C2 & Average \\
\hline Language knowledge & $38 \%$ & $38 \%$ & $32 \%$ & $38 \%$ & $50 \%$ & $37.5 \%$ & $39 \%$ \\
\hline Culture & $12 \%$ & $21 \%$ & $36 \%$ & $27 \%$ & $25 \%$ & $27.5 \%$ & $25 \%$ \\
\hline General knowledge & $50 \%$ & $32 \%$ & $32 \%$ & $35 \%$ & $25 \%$ & $35 \%$ & $30 \%$ \\
\hline & $100 \%$ & $100 \%$ & $100 \%$ & $100 \%$ & $100 \%$ & $100 \%$ & \\
\hline
\end{tabular}

Language knowledge possessed by learners has an important role in the ability to process information optimally. This supports learners to get information received both in quantity and quality. These findings are relevant to the concept of developing the BIPA Textbook internalizing language knowledge as declarative knowledge. With an average of $39 \%$, it shows that the proportion of linguistic knowledge is balanced against the cognitive needs of learners.

Culture as a manifestation of local wisdom in the form of community habits and cultural activities is an important leveraging factor in metacognitive knowledge. Culture is formed from various elements representing how a community develops. From the culture, a community is able to have a strong influence on individuals as members of the community both from the way of thinking, behaving, and acting. With a composition of $25 \%$, cultural knowledge in metacognitive construction in the BIPA Textbook is able to have an impact on learners. Learners have a reference to think based on community culture so that they are expected to be able to produce appropriate and acceptable thinking results by the community.

The general knowledge developed in the textbook is an important part of presenting recommendations for knowledge that must be possessed by learners. General knowledge has the function of forming the learner's understanding to find out the developing situation. From this, learners are expected to easily make adjustments properly and correctly to things that are generally applicable. So the existence of general knowledge in the circle of metacognitive knowledge is very important. A contribution of $36 \%$ is an ideal contribution in providing provision for the thinking process of learners to know things that are general in nature and 
make it easier for learners to carry out various universal activities.

b) Procedural Knowledge.
Procedural knowledge is the knowledge of how to do something, how to do the steps in a language problem solving process. The composition of procedural knowledge prepares the learner to create an object or carry out an activity with a sequence of steps required and suggested.

Table 2. Percentage of the Composition of Procedural Knowledge in the BIPA books

\begin{tabular}{|l|l|l|l|l|l|l|l|}
\hline & A1 & A2 & B1 & B2 & C1 & C2 & Average \\
\hline Language learning & $56 \%$ & $52 \%$ & $59 \%$ & $47 \%$ & $53 \%$ & $55 \%$ & $52 \%$ \\
\hline Daily activities & $54 \%$ & $48 \%$ & $41 \%$ & $53 \%$ & $47 \%$ & $45 \%$ & $48 \%$ \\
\hline & $100 \%$ & $100 \%$ & $100 \%$ & $100 \%$ & $100 \%$ & $100 \%$ & \\
\hline
\end{tabular}

The procedural knowledge discussed in the first BIPA Textbook is Language Learning. Language learning is included in the metacognition knowledge component as a reference in solving linguistic problems experienced by Learners. In linguistic learning, learners can learn gradually how to construct understanding so that they can easily understand linguistic concepts in a structured manner. The procedural found in the BIPA Textbook consists of steps to understand the concept of a definition, to compile a linguistic pattern properly, and how to work in completing language tasks. 52\% presence of procedural knowledge on language learning.

Next procedural knowledge is daily activities. In the findings of daily activities, learners can find procedural concepts in carrying out daily activities so that it helps in the process of translating cognition commands for psychomotor functions that must be carried out by learners. Knowledge of daily activities contained in the BIPA Textbook gradually provides appropriate education between the life of learners and the learning process faced by learners. This will directly support the acceptance of knowledge to learners, because the teaching material book has applicative properties or can be applied by learners in everyday life.

\section{c) Conditional Knowledge}

Conditional knowledge refers to a person's awareness of conditions affecting him in solving problems. Conditional knowledge is needed by learners in order to achieve maximum learning goals because in the concept of conditional knowledge, learners not only learn textual knowledge but are also equipped with contextual thinking.

Table 3. Percentage of Conditional Knowledge Composition in BIPA books

\begin{tabular}{|l|l|l|l|l|l|l|l|}
\hline & A1 & A2 & B1 & B2 & C1 & C2 & Average \\
\hline The use of language & $38 \%$ & $43 \%$ & $34 \%$ & $34 \%$ & $38 \%$ & $39 \%$ & $38 \%$ \\
\hline Cultural environment & $20 \%$ & $26 \%$ & $29 \%$ & $29 \%$ & $24 \%$ & $27 \%$ & $26 \%$ \\
\hline Knowledge of general condition & $42 \%$ & $31 \%$ & $37 \%$ & $37 \%$ & $38 \%$ & $34 \%$ & $36 \%$ \\
\hline & $100 \%$ & $100 \%$ & $100 \%$ & $100 \%$ & $100 \%$ & $100 \%$ & \\
\hline
\end{tabular}

The condition in the use of Indonesian is one factor that cannot be separated. With the accompanying factors such as conditions or language contexts, a sentence or discourse can be interpreted properly and completely. Different conditions can create different meanings. Learners need to know the right conditions in order to support the process of delivering information using the right language. In a structured manner, the BIPA Textbook provides knowledge about the conditions for using the right language. There are $38 \%$ of data findings indicating conditional knowledge with the concept of language use.

Cultural environment other than as an orientation effort towards Indonesian culture. The cultural environment contained in the BIPA Textbook explicitly shows the knowledge of the cultural environment 
prevailing in Indonesia. The findings of the data in the BIPA Textbook are $26 \%$ of the data from each book. This represents a good concentration in providing education to learners. The cultural environment will always exist and accompany every use of language in Indonesian society.

Conditionally, general knowledge is a thing that is rapidly changing and developing. It takes the right method in providing thoughts to the learners so that it does not have difficulty understanding the developing information. So the knowledge of general conditions that are present in the BIPA Textbook is an appropriate effort as an orientation to conditions generally applying in Indonesia. With a composition of $36 \%$ of each BIPA Textbook, it shows that books are the right media to present general knowledge to learners.

\section{DISCUSSION}

Declarative knowledge in the realm of the development of the metacognitive process of understanding has a very important role to provide a cognitive reference. Declarative knowledge provides a thinking reference in the form of textual knowledge about linguistic knowledge, cultural knowledge, and general knowledge. From the three findings, the data group strengthens the metacognitive processes possessed by learners in providing good knowledge so that it supports the process of receiving information, processing information, and cognitive follow-up which is channeled in the form of physical actions from speech or physical action.

Metacognitive processes require structured and complete construction so that one of the metacognitive knowledge that must be procedural knowledge. Procedural knowledge is an important element in providing an understanding of the processes or stages that must be applied in an applicable way before deciding to take an action. Then the procedural knowledge in the BIPA Textbook leads to the achievement of a solution to the task or problem faced by the Learners. Effectively, linguistic tasks and daily activities are key things which need to be well understood by learners. By knowing good procedures, learners will find it easier to do something or create something. This can also minimize the occurrence of technical errors both in completing language tasks and daily activities.

The next key in the metacognitive process is conditional knowledge. It is different from declarative knowledge and procedural knowledge which can be repetition easily because it only depends on the written text. Conditional knowledge related to conditions, situations, to the atmosphere in a discourse. Good habits and adaptability are needed in implementing conditional knowledge appropriately so as to produce metacognitive processes that are in line. This is closely related to the development of ways of thinking, behaving and feeling.
Metacognitive becomes the right mediator in shaping a person who is able to carry out their duties well because they are equipped with good knowledge, skills and attitudes. The learners' good way of thinking will know the process of planning actions, implementing actions, monitoring actions, and evaluating actions properly. Thus, the attitudes and feelings of learners who are more optimistic and confident are able to complete the learning process optimally.

\section{CONCLUSION}

BIPA Textbook as a medium for delivering knowledge. Metacognitive construction is needed as a machine capable of moving learners to accelerate the learning process. Declarative knowledge, procedural knowledge, and conditional knowledge as elements of knowledge that are connected in a metacognitive circle. Metacognitive knowledge tools are able to equip learners to internalize broad knowledge, process and manage knowledge, and employ knowledge in the form of productive activities.

\section{ACKNOWLEDGMENTS}

The publication of this proceeding article is a joint effort to improve the development of the BIPA Textbook. This research team would like to thank UNS Postgraduate Program and CoE Javanology for optimally facilitating and supporting this research.

\section{REFERENCES}

[1] Pannen, P. (1997). Pendidikan Sebagai Sistem. Jakarta: PAU-PPAI Universitas Terbuka

[2] Livingston, J., (1997). Metacognition: An overview.

[3] Wellman, H., (1985). The Origins of Metacognition. In D.L.Forrest-Pressley, G.E.MacKinnon, and T.G. Waller (eds.), Metacognition, Cognition, and Human Performance, volume 1 - Theoretical Perspectives, chapter 1. Academic Press, Inc.

[4] OZ, Huseyn. (2016). Metacoqnitive and academic motivation: A cross-sectional study in theacher education context of Turkey. Procedia- Social and Behavioral Science.232. 109-121.

[5] Koning. B.B., Ropb, G., \& Paasa, F. (2020). Learning from split-attention materials: Effects of teaching physical and mental learning strategies, Contemporary Educational Psychology: 61 (101873)

[6] Tamalene, H. (2010). Pembelajaran Matematika dengan Model CORE melalui Pendekatan Keterampilan Metakognitif untuk meningkatkan Kemampuan Penalaran Matematis Siswa SMP. 
Tesis pada Jurusan Pendidikan Matematika FPMIPA: Unpublished

[7] O’Neil \&Brown. (1997) Differential Effects of question Formats in Math assesment on Metacognition and Affect. Los Angeles: CRESSTCSE University of California.

[8] Anderson, O.W. \& Krathwohl, D.R., (2001). A Taxonomy for Learning, Teaching, and Assessing (A Revision of Bloom's Taxonomy of Educational Objectives). New York: Addison Wesley Longman, Inc.

[9] Wilson, D. \& Conyers, M. (2016). Teaching Students to Drive Their Brains. Virginia: ASCD

[10] Jones, R. N. (2003). Basic Counselling Skills: A Helper's Manual. London: Sage Publications.

[11] Kilinc. E. F. (2013). Investigation of relationship between self-esteem and metacognitive awareness level 9th grades students. Procedia- Social and Behavioral Science.106.1622-1628.

[12] Abdellah, R. (2015). Metacognitive awareness and its relation to academic achievement and teaching performance of pre-service female teachers in Ajman University in UAE. Procedia-Social and Behavioral Science.174.560-567.

[13] Lindlof, T. R. (1994). Qualitative Communication Research Methods. Thousand Oaks: SAGE Publisher.

[14] Mayring, P. (2014). Qualitative Content Analysis. Theoretical Foundation, Basic Procedures and Software Solution. Austria: Klagenfurt.

[15] Creswell, J. W. (2009). Research Design Qualitative, Quantitative, And Mixed Methods Approaches. London: SAGE Publications.

[16] Tracy, S. J. (2007). Qualitative Research Methods, Collecting Evidence, Crafting Analysis, Communicating Impact. Chichester: WilleyBlackwell

[17] Bogdan, C and Biklen, S.K. (2007). Qualitative Research for Education: An Introduction to Theory and Methods (Fifth Edition). Boston Mass: Pearson Education, Inc.

[18] Dawson, C. (2002). Practical Research Methods. Oxford: How to Books.

[19] Howitt, D. \& Cramer, D. (2017). Research Methods in Psychology. Edinburgh: Pearson Education Limited.

[20] Ridwan, M., Dewi,G.L. \& Mohamad, B. (2016). The Attitude of Egyptian Arabic Speakers Towards
Standard Arabic and Egyptian Arabic. Advanced Science Letters 22 (12), 4374-4377. 